\title{
Solid-phase microextraction and gas chromatography for rapid analysis of pesticides
}

\author{
C. Miège and J. Dugay \\ École Supérieure de Physique et Chimie Industrielles de Paris (ESPCI), Laboratoire Environnement et Chimie Analytique \\ (ERS CNRS 657), 10 rue Vauquelin, 75231 Paris Cedex 05, France
}

Solid-phase microextraction (SPME) combined with gas chromatography (GC) is a fast and simple technique for the handling of aqueous samples using coated fused-silica fibres. Fully automated devices are commercially available. Several applications have demonstrated the potential of the technique for both screening and quantification of pesticides in water samples with detection limits in the range from 5 to $100 \mathrm{ng} / \mathrm{L}$ using mass spectrometry detection.

$\mathrm{M}$ any pesticides can be analysed by gas chromatography but their detection and quantification in water samples at the $0.1 \mu \mathrm{g} / \mathrm{L}$ level require an extraction and enrichment step. This step is often carried out using liquid-liquid extraction (LLE) or solid-phase extraction (SPE). LLE requires large amount of organic solvent and has been largely replaced these recent years by SPE using a variety of different sorbents. Although the on-line coupling of SPE with GC is possible, it is not as easy as that involved with liquid chromatography (LC), for which several fully automated devices have been commercially available for several years. Anyway, SPE followed by GC analysis is commonly an off-line multi-step procedure proned to losses of analytes and still needed some organic solvent for analyte elution.
Moreover, only an aliquot of the extract is injected into the gas chromatograph.

Solid-phase microextraction (SPME) was introduced several years ago by Pawliszyn and co-workers [1] and represents a further advance as a complete solvent-free alternative technique which is well adapted to the extraction of pesticides from water samples. Organic compounds are simply extracted by dipping the solid phase coating of a silica fibre support into an aqueous solution. Extraction and concentration are then focused in a single step. Then the fibre is transferred into the heated injector of a gas chromatograph where the extracted analytes are thermally desorbed and analysed. Contrary to SPE, the total amount of extracted sample is used for the determination by GC. SPME requires small sample volumes (1 to $15 \mathrm{~mL}$ ), and several fibres with different polarities are now available. Moreover, the technique is easy to automate by using a commercially available auto-sampler.

A recent review [2] and the increasing number of papers devoted to this technique published these last two years, witnesses its increasing use especially in the environmental field [3-11]. The first pesticides applications concerned the more volatile organichlorinated insecticides and used an electron-capture detector (ECD) [3]. Then, many applications were devoted to nitrogen- and phosphorous-containing pesticides because of the selectivity of the nitrogen-phosphorus detector (NPD) [4-6]. Some recent publications reported the use of mass spectrometric (MS) detector and are devoted to more numerous pesticides [7-11]. 


\section{Description of the SPME procedure}

The SPME device is consisted in part on a conventional syringe which makes the system portable. This syringe is used as a holder for the fibre assembly which includes a hollow needle protecting a small-diameter fused silica fibre (internal diameter of $110 \mu \mathrm{m}$ ) that has been coated with a polymeric stationary phase (thickness varying between 7 to $100 \mu \mathrm{m})$. After piercing the septum of the sample vial, the coated fibre protected in the hollow needle is deployed into the vial. As soon as the extraction is completed, the fibre is retracted back into the hollow needle and the fibre assembly is introduced in the GC injector using the syringe assembly. After piercing the septum of the GC injector, the coated fibre protected in the needle is deployed again into the injector and analytes are thermally desorbed and analysed. Because the fibre has been cleaned efficiently while desorbing any contaminants in the GC injector, it can immediately be used for the next analysis. The same fibre could be used up to 30 times for surface water to 100 times for distilled water [4].

The miniature cylindrical geometry of the SPME device permits a rapid mass transfer during the extraction and the desorption of the concentrated extract into the GC system. During the extraction step, the target analytes partition from the aqueous sample matrix into the polymeric coating. SPME belongs to solid-phase extraction methods but the process operates differently. In classical SPE, a known sample volume is percolated through a solid sorbent and the extraction mechanism is closed to a liquid chromatographic process. It is easy to predict the compounds that would be extracted with good recoveries by considering the chromatographic data or the analyte's retention time using the extraction phase of interest as an analytical stationary phase. The process involved in SPME is different and is based on a partition process. A first consequence is that analytes are extracted according to their partition coefficients. Therefore, extraction recoveries are never $100 \%$ and the partition equilibrium may require some time to be reached.

SPME can be operated in the headspace mode when analytes are volatile, the SPME fibre is then exposed to the gaseous space above the aqueous sample. For semi-volatile analytes the SPME fibre is completely immersed into the aqueous matrix. In this paper, only aqueous extractions will be considered since pesticides are mainly semi-volatile compounds.

\section{Amount extracted and partition coefficients}

The theoretical partition process has been extensively studied. In a finite volume of sample, $V_{\text {aq, }}$, the number of moles of analytes extracted by the fibre at the equilibrium, $n_{\mathrm{s}}$, is dependant on the initial analyte's concentration in solution, $C_{\text {aq }}$, according to:

$$
n_{\mathrm{s}}=\frac{K V_{\mathrm{s}} V_{\mathrm{aq}} C_{\mathrm{aq}}}{K V_{\mathrm{s}}+V_{\mathrm{aq}}}
$$

where $K$ is the partition coefficient at equilibrium of the analyte between the stationary phase with a volume $V_{\mathrm{s}}$ and the aqueous phase.

The dynamic of such a model has been modelled for both stirring and unstirring conditions and the model predicts rapid extraction if the solution is completely mixed. Without mixing the equilibrium is limited by the analyte diffusion in water. Therefore extractions are always performed under stirring conditions. Former autosamplers required the use of a small magnetic bar in each vial, but the recent ones include the stirring of the fibre [12].

The higher the affinity for an analyte towards a coating, the higher the $K$ value associated, and the larger the amount of the extracted analyte at equilibrium. Various factors can influence the SPME efficiency. During the extraction step, the ionic strength and the $\mathrm{pH}$ of the aqueous sample, the nature and the thickness of the fibre, the stirring conditions and the temperature of the extraction must be optimised. During the desorption step, the temperature of the GC injector and the length of time desorption must be considered.

\section{Effects of the various parameters}

\section{lonic strength and adjustment of the $\mathrm{pH}$ of the sample}

The modification of the ionic strength is to be considered for the extraction of water-soluble analytes. Actually, the more soluble in water the analyte, the lower his affinity for the fibre. Then, the amount extracted by the fibre can be increased by reducing the solubility of the analyte in water, which can be achieved by an addition of a salt or when analytes are ionisable by a $\mathrm{pH}$ adjustment corresponding to their molecular form. Very often, sodium chloride is added at a concentration in a range from 2 to $4 \mathrm{M}$.

\section{Equilibrium times}

Equilibrium times are usually determined from time profiles which consist in reporting on a graph the peak area obtained or amount extracted, when varying the extraction time from a few minutes to an hour or more. Time profiles are dependant on the nature and the thickness of the fibre, as well as on the analyte.

Two examples of time profile curves are given figure 1 for atrazine and terbutryn using a fibre (PDMS) with three different thicknesses. Several effects can be observed. First, the extracted amount increases with the thickness of the fibre, but not in a similar ratio. Second, the time required to reach equilibrium depends on the compound. Using the $100 \mu \mathrm{m}$ fibre and similar experimental conditions, equilibrium is observed in less than 30 minutes for atrazine whereas more than 100 minutes are required for terbutryn. The amount extracted at the equilibrium is also very different: 7 $\mathrm{ng}$ and $100 \mathrm{ng}$ are respectively extracted for these two compounds although the initial contents were the same (550 ng).

Several studies have shown that a shorter time than the equilibrium time can be selected provided that the extraction are timed carefully to prevent from deviations of the amount extracted. The time has also to be selected in order to extract 
quantities which are high enough to attain limits of detection during the GC run with the selected detector. In many applications where SPME is performed with an autosampler, the extraction times are often equal to the time required for the analysis. Thus, the extraction of a sample occurs during the GC run of the previous one. Typical extraction times are in a range from 20 to 40 minutes, when several pesticides are to be determined in the same sample.

\section{Selection of the nature and thickness of the fibre}

Various fibres with different polarities and thicknesses are commercialised:

- Polydimethylsiloxane (PDMS), 7, 30 and $100 \mu \mathrm{m}$.

- Polydimethylsiloxane-divinylbenzene

(PDMS-DVB) $65 \mu \mathrm{m}$.

- Polyacrylate (PA) $85 \mu \mathrm{m}$.

- Carbowax-divinylbenzene (CW-DVB) $65 \mu \mathrm{m}$.

- Carboxen-polydimethylsiloxane (CX-PDMS) $75 \mu \mathrm{m}$.

In a first approximation, the selection of the fibre is guided by the nature of the analytes. PDMS and PDMSDVB are considered as the less polar coatings, whereas CWDVB has an intermediate polarity and PA is the more polar coating. CX-PDMS is more appropriate for small and rather volatile molecules. The non polar PDMS was preferred for the extraction of the non-polar pesticides with low solubility in water such as organochlorines and some of the non polar organophosphorus pesticides, whereas the more polar polyacrylate fibre was shown to be more appropriate for the more polar nitrogen-containing herbicides.

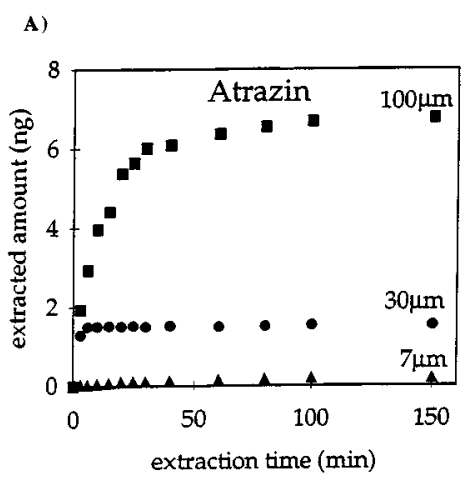

B)

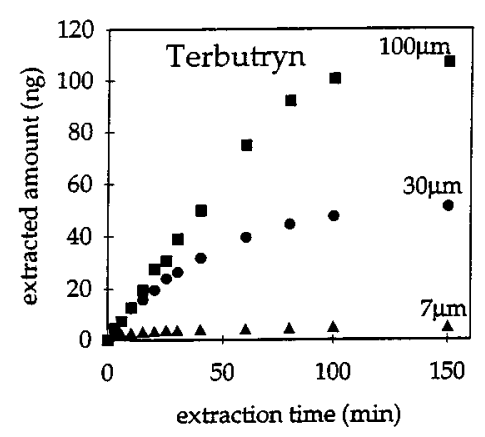

Figure 1. Time profile curves of $A$ ) atrazine and $B$ ) terbutryne with PDMS fibres at 7, 30 and $100 \mu \mathrm{m}$.The initial quantity is $\mathbf{5 5 0}$ $\mathrm{ng}$ for each of the two pesticides. From [4].
The thickness of the fibre has an important effect on the $n_{\mathrm{s}}$ value as shown in figure 1 . If the molecular diffusion coefficient of the analytes within the polymeric fibre $\left(D_{\mathrm{s}}\right)$ is not a limiting factor, then the larger the fibre, the higher the amount of analyte extracted at equilibrium. Figure 1 points out that comparison of extracted amount and time required for equilibrium should be done with equivalent thicknesses, which is not possible since fibres are not necessarily available with similar thicknesses. Taking this effect into account, four different fibres, PDMS, PDMS-DVB, PA and CW-DVB were compared for the extraction of pesticides having a wide range of water solubilities and polarities [4]. Although the affinity order, as measured by the partition coefficient, were different towards the four coatings, no correlation was established between the characteristics of the fibres and those of the solutes. The two fibres containing divinylbenzene were shown to have the highest affinities for the more polar analytes. An interlaboratory study (including ten laboratories) about the analysis of triazine herbicides and their metabolites has been reported [13]. The SPME conditions were optimised in order to obtain maximum sensitivity. The salt addition $(0.3 \mathrm{~g} / \mathrm{mL} \mathrm{NaCl})$ and the choice of the CW-DVB fibre were shown to especially increase the sensitivity.

\section{Desorption conditions}

During the desorption process, the temperature of the GC injector must be high enough and the desorption time must be long enough to completely desorb the totality of the extracted analytes. Nevertheless, a maximal temperature is recommended by the suppliers to avoid the degradation of the polymeric fibre. Typical desorption temperatures are $250-300{ }^{\circ} \mathrm{C}$ during 3 to 5 minutes. These conditions allow to achieve complete desorption in real unknown samples and to clean the fibre between experiments. Anyway, complete cleaning of the fibre can be easily achieved by including blank run after each real sample run, especially when contaminated samples are handled.

\section{Quantitative analysis and validation by interlaboratory studies}

SPME was first considered as a screening method because of the influence of matrix effects and the competition on the partition process that must be taken into account when quantification is considered. Quantitative measurements can be done if standardisation of the detector has been carried out in order to have the real extracted amount. Standardisation is usually performed by analysing solution spiked with a mixture prepared with a known amount of analytes. With an on-line SPME-GC-NPD procedure, it has been verified that the calibration curves were similar when one analyte of interest was present on its own in a drinking water sample, or when eleven other pesticides were present at the same concentration, or when two other pesticides were present at a ten times higher concentration $(500 \mu \mathrm{g} / \mathrm{L}$ instead of $50 \mu \mathrm{g} / \mathrm{L}$ ) [4]. Linearity was obtained over a wide range from 0.1 to $50 \mu \mathrm{g} / \mathrm{L}$ when one proceeds with the CW-DVB fibre, an extraction time of $30 \mathrm{~min}$ and a sample volume of $11 \mathrm{~mL}$ with addition of $\mathrm{NaCl} 4 \mathrm{M}$. The same study indicated that most of the pesticides were extracted in a range from 0.5 to $10 \mu \mathrm{g} / \mathrm{L}$ with $\mathrm{RSD}$ values in a range from 2 to $15 \%$. 
This precision is in agreement with the reported values in the literature using GC-NPD.

Nevertheless, in order to achieve quantitative analysis, it is important to use separate vials for each experiment. Consecutive experiments in the same vial lead to non-reproducible results because the amount extracted can represent as much as 20 to $30 \%$ of the initial amount in the sample.

As already mentioned, an inter-laboratory validation of SPME for the determination of triazines and their metabolites at the $\mathrm{ng} / \mathrm{L}$ in water samples was recently reported [13]. Optimised conditions for sensitivity were obtained using the CW-DVB fibre and an extraction time of $30 \mathrm{~min}$. The average detection limits using GC-MS were in a range from 4 to $24 \mathrm{ng} / \mathrm{L}$ for seven common triazine herbicides and 20 and $40 \mathrm{ng} / \mathrm{L}$ for deisopropylatrazine and desethylatrazine respectively. Relative repeatability and reproducibility standard deviations ranged from 6 to $14 \%$ and from 10 to $17 \%$ respectively. The comparison of the determined concentrations of the reference sample with the "true" values of the analytes (in a range from 50 to $120 \mathrm{ng} / \mathrm{L}$ ) allowed to demonstrate the good accuracy of the method in drinking water.

\section{Selected examples of analysis of pesticides in water samples}

\section{Nitrogen- and phosphorous containing pesticides}

This group is often selected because it corresponds to pesticides included in the US EPA methods 507 and 508, which involve GC with NPD detection after an extraction step.

A group of 22 nitrogen-containing pesticides have been characterised in ultrapure water samples by manual sampling SPME coupled with GC-MS, GC-NPD and GC-FID [7]. Those pesticides can be divided into various subgroups according to their chemical structure: triazines, nitroanilines, substituted uracils, thiocarbamates, and several other pesticides containing both nitrogen and chlore atoms that will be treated later in this paper. The polyacrylate fibre $(85 \mu \mathrm{m})$ was used and was immersed at ambient temperature during a 50 minutes extraction under stirring conditions. The $4 \mathrm{~mL}$ sample of ultrapure water containing the pesticides was set at $\mathrm{pH} 2$ and the ionic strength was set at $1 \mathrm{~g} / \mathrm{mL}$ of $\mathrm{NaCl}$. The desorption of the analytes in the GC injector lasted 5 minutes at $230{ }^{\circ} \mathrm{C}$. Limits of detection (LODs) have been evaluated and are reported table I, as well as those obtained by the conventional EPA methods. LODs are generally improved by three orders of magnitude using MS compared with FID. The RSD values range from 2 to $20 \%$ and can be expected lower with the use of an autosampler. Anyway, these values are lower than $30 \%$ which is the maximum RSD value accepted by the EPA. The linearity obtained with the 3 procedures was shown to be good in the range of 0.1 to $1000 \mathrm{ng} / \mathrm{mL}$, with linear regression coefficients higher than 0.99 for 21 of the 22 studied pesticides. The MS (iontrap) chromatogram is shown in figure 2.

Another group of selected nitrogen-containing pesticides has been analysed by SPME-GC-MS [10]. Those compounds are ametryn, atrazine, prometryn, terbutryn and molinate. They were extracted with the polyacrylate fibre $(85 \mu \mathrm{m})$ immersed at $55^{\circ} \mathrm{C}$ during 45 minutes under stir-
Table I. Limits of detection ( $\mathrm{ng} / \mathrm{L}$ ) for the 22 selected nitrogen-containing pesticides in ultrapure water subjected to SPME-GC coupled with a FID, NPD or MS detection. Limits of detection obtained by the US EPA methods 507 and 508, from [7].

\begin{tabular}{|c|c|c|c|c|}
\hline Herbicide & $F I D^{a}$ & $N P D^{b}$ & $M S^{c}$ & US EPA 507/508 \\
\hline EPTC (1) & 2000 & 50 & 0.8 & 200 \\
\hline Butylate (2) & 1000 & 20 & 0.1 & 100 \\
\hline Vernolate (3) & 1000 & 20 & 0.5 & 100 \\
\hline Pebulate (4) & 1000 & 20 & 1 & 100 \\
\hline Molinate (5) & 2000 & 60 & 0.3 & 100 \\
\hline Propachlor (6) & 6000 & 800 & 15 & 500 \\
\hline Cycloate (7) & 800 & 20 & 0.05 & 200 \\
\hline Trifluralin (8) & 400 & 30 & 0.02 & 20 \\
\hline Benfluralin (9) & 300 & 30 & 0.4 & $N A^{d}$ \\
\hline Simazine (10) & 1000 & 70 & 1 & 100 \\
\hline Atrazine (11) & 7000 & 40 & 3 & 100 \\
\hline Propazine (12) & 10000 & 50 & 0.3 & 100 \\
\hline Profluralin (13) & 200 & 30 & 0.1 & $N A^{d}$ \\
\hline Terbacil (14) & 15000 & 200 & 1 & 4500 \\
\hline Metribuzin (15) & 14000 & 200 & 3 & 100 \\
\hline Bromacil (16) & 19000 & 400 & 0.1 & 2500 \\
\hline Metolachlor (17) & 1000 & 200 & 0.01 & 700 \\
\hline Isopropalin (18) & 300 & 10 & 0.1 & $N A^{d}$ \\
\hline Pendimethalin (19) & 200 & 20 & 0.1 & $N A^{d}$ \\
\hline Oxadiazon (20) & 300 & 30 & 0.01 & $N A^{d}$ \\
\hline Oxyfluorofen (21) & 200 & 300 & 6 & $N A^{d}$ \\
\hline Hexazinone (22) & 2000 & 6000 & 1 & 800 \\
\hline
\end{tabular}

a: determined from $100 \mu \mathrm{g} / \mathrm{L}$ samples

b: determined from $10 \mu \mathrm{g} / \mathrm{L}$ samples

c: determined from $10 \mathrm{ng} / \mathrm{L}$ samples

d: Not Applicable, i.e. not analysed by EPA 507 or 508 .

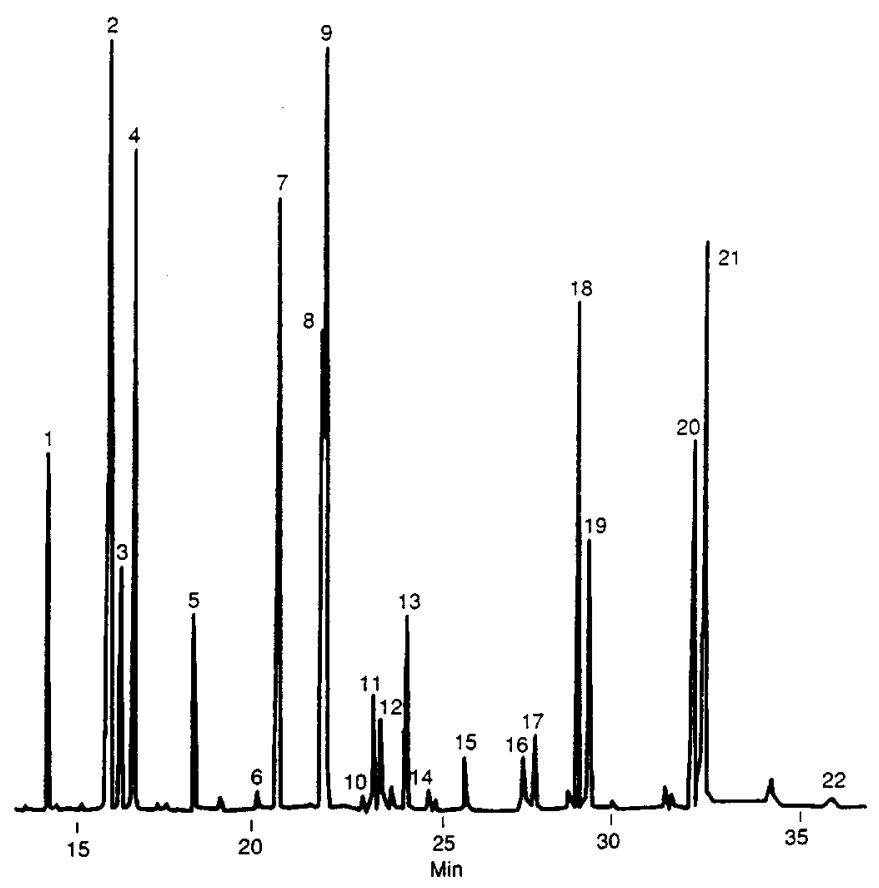

Figure 2. SPME-GC-MS analysis of the 22 herbicides spiked at $100 \mathrm{ng} / \mathrm{mL}$ in ultrapure water, mass spectral detection with total ion plot. From [7]. For peak identification, see table I. 
ring conditions. The ionic strength was adjusted at $5 \mathrm{~g} / \mathrm{L}$ of $\mathrm{NaCl}$. The desorption lasted 2 minutes at $250{ }^{\circ} \mathrm{C}$. The $\mathrm{MS}$ detection was performed with both SIM (selected ion monitoring) and full-scan acquisition modes. The linearity with the correlation coefficients and the repeatability of the method were good. LODs were estimated with spiked drinking water samples and ranged from 0.01 to $0.2 \mu \mathrm{g} / \mathrm{L}$ with full-scan acquisition mode and from 0.002 to $0.01 \mu \mathrm{g} / \mathrm{L}$ with SIM acquisition mode. The two MS chromatograms are shown in figure 3.

The 39 nitrogen and phosphorus-containing pesticides listed in the US EPA method 507 have been characterised by SPME-GC-MS and SPME-GC-NPD, spiked at $10 \mu \mathrm{g} / \mathrm{L}$ level in drinking water [9]. The PDMS $(100 \mu \mathrm{m})$ fibre was used, with an extraction time of 20 minutes at ambient temperature under stirring conditions. The $4 \mathrm{~mL}$ water samples were set at $\mathrm{pH} 7$ and the desorption lasted 5 minutes at $220{ }^{\circ} \mathrm{C}$. The cor responding NPD chromatogram is shown in figure 4 where we can observe 36 of the 39 pesticides since disulfoton sulfoxide, mevinphos and fluridone have higher limits of detection than $10 \mu \mathrm{g} / \mathrm{L}$. The LODs have been reported in table II, as well as the LODs obtained by the US EPA. As many as 34 of the 39 pesticides were measured at levels lower than those of the EPA method 507, showing thus the ability of the SPME-GC-NPD procedure for monitoring drinking water in United States.

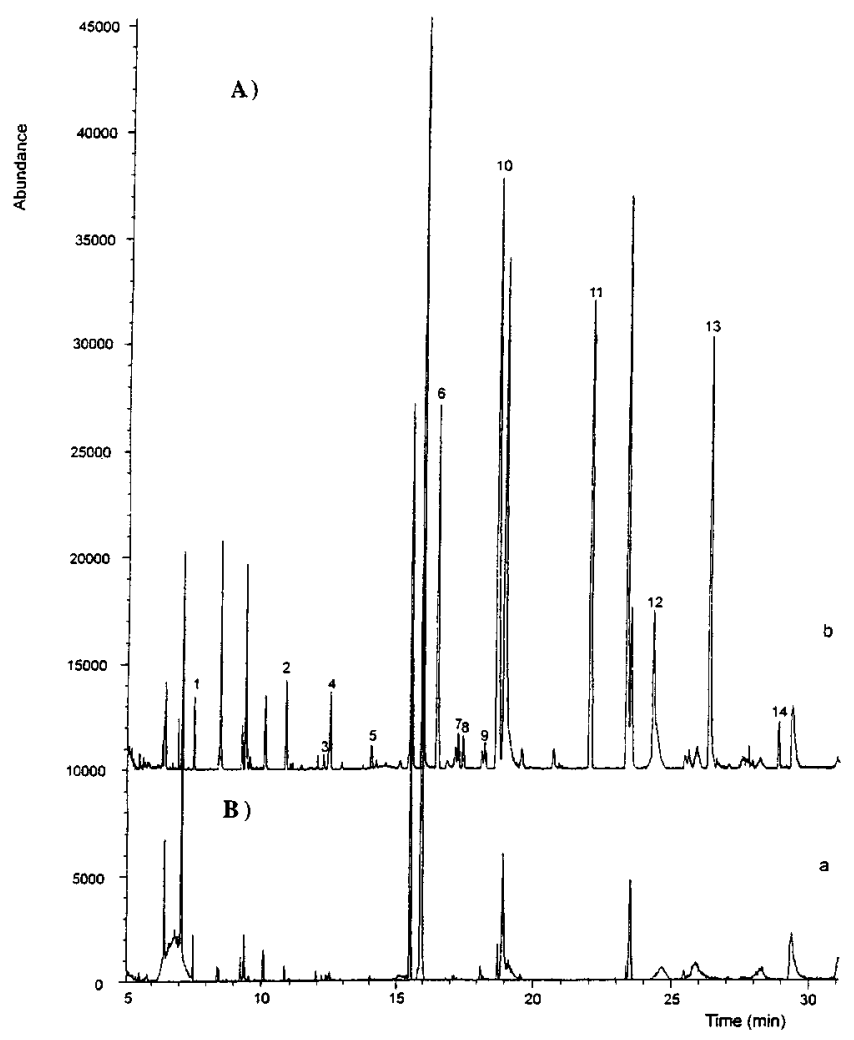

Figure 3. SPME-GC-MS (full-scan) analysis a) of drinking water spiked with pesticides at $0.5 \mu \mathrm{g} / \mathrm{L}, \mathrm{b}$ ) of non spiked drinking water. From [10]. Peak identification: molinate $=1, \alpha-\mathrm{HCH}=2$, atrazine $=3$, lindane $=4, \delta-\mathrm{HCH}=5$, heptachlor $=6$, ametryn $=$ 7 , prometryn $=8$, terbutryn $=9$, aldrin $=10$, heptachlor-endosulfan $=11, \alpha$-endosulfan $=12$, dieldrin $=13, \beta$-endosulfan $=14$.
Table II. Limits of detection (ng/L) for the US EPA 507 pesticides spiked at $100 \mu \mathrm{g} / \mathrm{L}$ in drinking water subjected to SPME-GC coupled with NPD or MS detection. Limits of detection obtained by the US EPA methods 507, from [9].

\begin{tabular}{|c|c|c|c|}
\hline Pesticides & $N P D$ & $M S$ & US EPA 507 \\
\hline Dichlorvos (1) & 1500 & 80 & 2500 \\
\hline EPTC (2) & 20 & 10 & 250 \\
\hline Disulfoton sulfoxide & 37000 & 8100 & 380 \\
\hline Butylate (3) & 50 & 20 & 150 \\
\hline Vernolate (4) & 100 & 20 & 130 \\
\hline Mevinphos & 22000 & 4300 & 5000 \\
\hline Pebulate (5) & 40 & 10 & 130 \\
\hline Molinate (6) & 110 & 20 & 150 \\
\hline Cycloate (7) & 130 & 30 & 250 \\
\hline Ethoprop (8) & 30 & 10 & 190 \\
\hline Chlorpropham (9) & 220 & 40 & 500 \\
\hline Simazine (10) & 360 & 10 & 75 \\
\hline Atraton (11) & 400 & 40 & 600 \\
\hline Prometon (12) & 160 & 20 & 300 \\
\hline Atrazine (13) & 110 & 30 & 130 \\
\hline Propazine (14) & 40 & 10 & 130 \\
\hline Terbufos (15) & 80 & 10 & 500 \\
\hline Pronamide (16) & 650 & 20 & 760 \\
\hline Diazinon (17) & 60 & 10 & 250 \\
\hline Disulfoton (18) & 40 & 10 & 300 \\
\hline Disulfoton sulfone (19) & 8200 & 1100 & 3800 \\
\hline Ametryn (22) & 400 & 30 & 2000 \\
\hline Simetryn (20) & 180 & 20 & 250 \\
\hline Alachlor (21) & 300 & 10 & 380 \\
\hline Prometryn (23) & 20 & 10 & 190 \\
\hline Terbutryn (24) & 10 & 10 & 250 \\
\hline Metolachlor (25) & 220 & 20 & 750 \\
\hline Triadimefon (26) & 120 & 10 & 650 \\
\hline MGK 264 (27) & 380 & 30 & 500 \\
\hline Diphenamid (28) & 260 & 30 & 600 \\
\hline Butachlor (29) & 250 & 10 & 380 \\
\hline Carboxin (30) & 9500 & 3500 & 600 \\
\hline Stirofos (31) & 250 & 20 & 760 \\
\hline Fenamiphos (32) & 150 & 50 & 1000 \\
\hline Napropamide (33) & 130 & 30 & 250 \\
\hline Merphos (34) & 130 & 20 & 250 \\
\hline Norflurazon (35) & 180 & 30 & 500 \\
\hline Fenamirol (36) & 220 & 20 & 380 \\
\hline Fluridone & 27000 & 2500 & 3800 \\
\hline
\end{tabular}

In Europe, required detection limits are much lower than in United States since the concentration of individual pesticide and toxic transformation products in drinking water and surface water used for drinking purpose are limited by the European Community (EC) to $0.1 \mu \mathrm{g} / \mathrm{L}$. The performance of the on-line SPME-GC-NPD methods has been evaluated with 12 selected nitrogen- and phosphorus-containing pesticides in drinking and river Seine water samples [4]. The CW-DVB $(65 \mu \mathrm{m})$ fibre provided the highest sensitivity, with an extraction time of 30 minutes at ambient temperature under stirring conditions. The $11 \mathrm{~mL}$ water samples were set at $\mathrm{pH} 7$ and the ionic strength was fixed at $4 \mathrm{M}$ with 


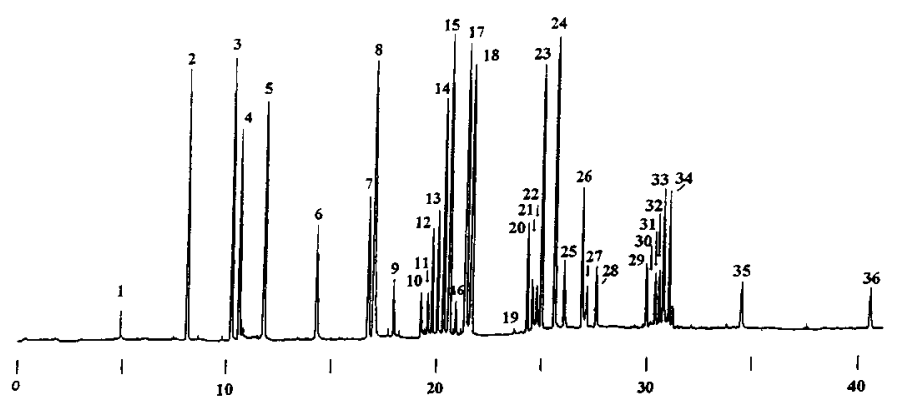

Figure 4. SPME-GC-NPD analysis of 36 of the 39 pesticides listed in US EPA 507 spiked at $10 \mu \mathrm{g} / \mathrm{L}$ in drinking water. From [9]. For peak identification see table II.

$\mathrm{NaCl}$. The desorption lasted 2 minutes at $280{ }^{\circ} \mathrm{C}$. LODs for drinking and river Seine water samples as well as the precision of the method (RSD) are reported table III. LODs range from 0.02 to $0.3 \mu \mathrm{g} / \mathrm{L}$ for drinking water samples which is lower than those obtained in table II. For river Seine water samples, LODs range from 0.04 to $0.7 \mu \mathrm{g} / \mathrm{L}$. RSD values are below $10 \%$ except for EPTC, Vernolate and Cycloate which have been proved to be instable and degradable during the SPME process [4]. Figure 5 shows the chromatogram corresponding to the river Seine water sample, non-spiked and spiked with $1 \mu \mathrm{g} / \mathrm{L}$ of each of the 12 pesticides. The river Seine water sample is quite contaminated, and the relatively clean corresponding chromatogram is due, in part, to the selectivity of the NPD. When considering the LODs reported for drinking water in table III and taking into account that quantification at $0.1 \mu \mathrm{g} / \mathrm{L}$ required LODs at least three times lower, then only dichlorvos, prometon, atrazine, terbutryne, triadimefon and fenamiphos can be monitored in drinking water using SPME-GC-NPD. For the

Table III. Limits of detection ( $\mathrm{ng} / \mathrm{L}$ ) for selected pesticides in drinking and river Seine water subjected to SPME-GCNPD, limits of detection obtained by US EPA method 507 and residual standard deviation (RSD, \%), from [4].

\begin{tabular}{lccc}
\hline Pesticides & drinking water & river Seine water & \\
& & $R^{c}$ \\
\hline Dichlorvos (1) & 30 & 80 & 9 \\
EPTC (2) & 200 & 500 & 15 \\
Vernolate (3) & 300 & 700 & 18 \\
Cycloate (4) & 200 & 500 & 13 \\
Prometon (5) & 40 & 100 & 3 \\
Atrazine (6) & 30 & 60 & 3 \\
Terbutryne (7) & 30 & 60 & 6 \\
Metolachlor (8) & 200 & 400 & 4 \\
Triadmefon (9) & 40 & 100 & 8 \\
Fenamiphos (10) & 20 & 40 & 6 \\
Napropamide (11) & 100 & 200 & 8 \\
Norflurazon (12) & 100 & 200 & 6 \\
\hline
\end{tabular}

a: determined from $0.1 \mu \mathrm{g} / \mathrm{L}$ samples

b: determined from $1 \mu \mathrm{g} / \mathrm{L}$ samples

c: for $n=6$.
6 other pesticides and according to the values in tables I and II, quantification at $0.1 \mu \mathrm{g} / \mathrm{L}$ level requires the SPME-GCMS coupling. Actually, this procedure can be a routine method well adapted for both confirmation of pesticide identity and rapid monitoring of drinking water at $0.1 \mu \mathrm{g} / \mathrm{L}$ level required by EC regulations.

\section{Organochlorine pesticides}

Chlorinated pesticides have also been characterised using manual device SPME coupled with GC-ECD analysis [3]. The PDMS $(100 \mu \mathrm{m})$ fibre was immersed at ambient temperature in $4 \mathrm{~mL}$ water samples for 15 minutes under stirring conditions. The desorption of the analytes lasted 3 minutes at $260{ }^{\circ} \mathrm{C}$. Figure 6 shows the two chromatograms corresponding to 21 chlorinated pesticides spiked at $200 \mathrm{ng} / \mathrm{L}$ in drinking water or at $500 \mathrm{ng} / \mathrm{L}$ in hazardous waste. LODs in drinking water have not been reported but can be evaluated in the low ppt level. The background in chromatogram (B) is due to the high contamination of the waste sample. However, quantification of the chlorinated pesticides in this hazardous waste remains possible at a level ranged from 0.05 to $0.4 \mu \mathrm{g} / \mathrm{L}$. In this case, SPME can be used as an efficient and rapid screening method possibly on site or to precede a more precise analyse by GC-MS. SPME
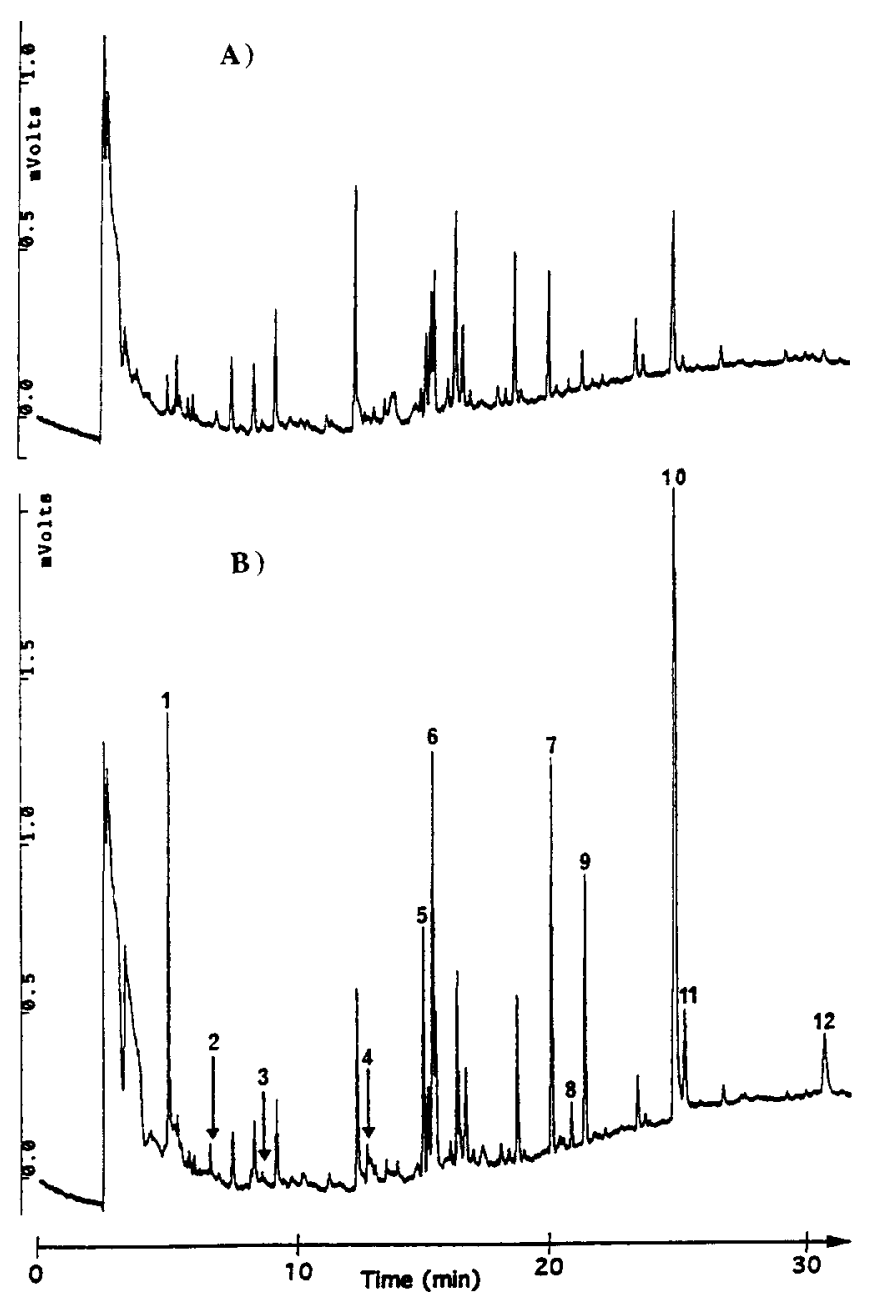

Figure 5. SPME-GC-NPD analysis of the 12 selected pesticides listed in US EPA 507, a) non spiked, b) spiked at $1 \mu \mathrm{g} / \mathrm{L}$ in river Seine water. From [4]. For peak identification, see table III. 
A)

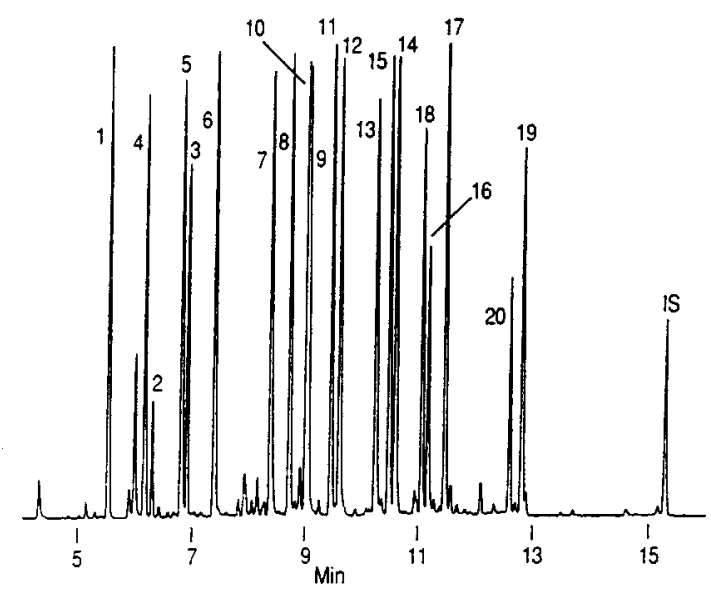

B )

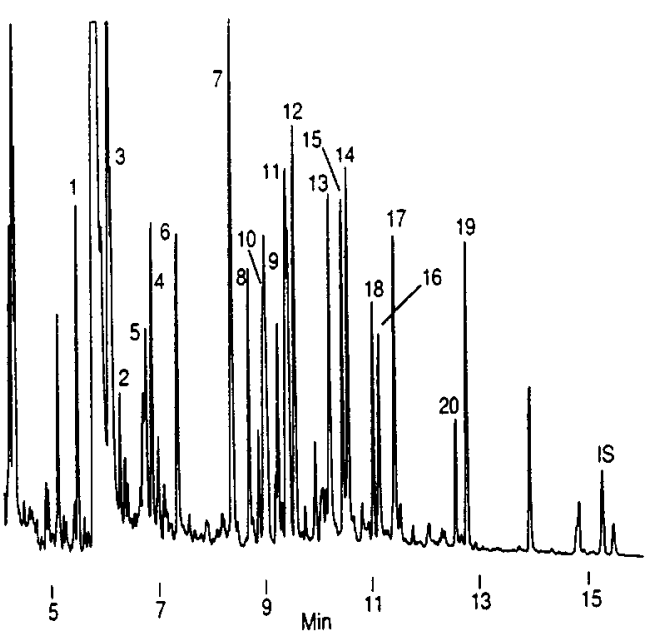

Figure 6. SPME-GC-ECD analysis of the 20 selected chlorinated pesticides A) spiked at $200 \mu \mathrm{g} / \mathrm{L}$ in drinking water, B) spiked at $500 \mu \mathrm{g} / \mathrm{L}$ in hazardous waste. From [3]. Peak identification: $\alpha-$ $\mathrm{BHC}=1, \beta-\mathrm{BHC}=2, \gamma-\mathrm{BHC}=3, \delta-\mathrm{BHC}=4$, heptachlor $=5$, aldrin $=6$, heptachlor epoxide $=7, \gamma$-chlordane $=8$, endosulfan $\mathrm{I}=9$, $\alpha$-chlordane $=10,4,4^{\prime}-\mathrm{DDE}=11$, dieldrin $=12$, endrin $=13$, endosulfan II = 14, 4, 4'-DDD = 15, endrin aldehyde $=16$, endosulfan sulfate $=17,4,4$ ' DDT $=18$, endrin ketone $=19$, methoxychlor $=20$, decachlorobiphenyl $=$ internal standard or IS.

can for example rapidly highlight the necessity to dilute a sample before a GC-MS analysis.

Chlorinated pesticides have also been analysed by SPMEGC-MS with both SIM and full-scan acquisition modes [10]. Those compounds are $\alpha-\mathrm{HCH}, \delta-\mathrm{HCH}$, lindane, aldrin, dieldrin, $\alpha$-endosulfan, $\beta$-endosulfan, heptachlor and heptachlor epoxide. The linearity with the correlation coeffi- cients and the repeatability of the method were good. LODs were estimated with drinking water in the range of 0.01 to $0.02 \mu \mathrm{g} / \mathrm{L}$ with full-scan acquisition mode and 0.002 to 0.01 $\mu \mathrm{g} / \mathrm{L}$ with SIM acquisition mode. The two chromatograms of these procedures are shown in figure 3. Figure 2 also included some organochlorine compounds, and LODs reported on table I can be compared for FID, NPD and MS detections.

\section{Conclusion}

SPME is an efficient solvent-free technique for the handling of aqueous samples prior to GC analysis. The method has several advantages such as simplicity, low cost, rapidity and the sensitivity of the combination of SPME-GC with appropriate detection modes. SPME can be successfully performed as a rapid screening method or as a quantitative one for trace determination of pesticides in water samples. Quantitative analysis can be performed provided that careful calibration with spiked solutions has been performed previously using exactly the same conditions as those used for running unknown samples. Limits of detection for quantification at the $0.1 \mu \mathrm{g} / \mathrm{L}$ level, as required by the EC regulations for the pesticides in water samples, are easily achieved with MS detection. Because SPME is a partition process, the co-extraction of humic substances and therefore the background on the chromatograms are reduced. Wastewater samples, for example, can be screened on site before a more accurate analysis on laboratory.

\section{References}

1. Belardi, R. P.; Pawliszyn, J. Water Pollution Research J. Canada. 1989, 24, 179.

2. Eisert, R.; Levsen, K. J. Chrom. A. 1996, 733, 143.

3. Shirey, R. Supelco 1995, 14, 4.

4. Dugay, J.; Miège, C.; Hennion, M. C. J. Chrom. A. 1998, 795, 27.

5. Barnabas, I. J.; Dean, J. R.; Fowlis, I. A.; Owen, S. P. J. Chrom. A. 1995, 705, 305.

6. Lopez-Avila, V.; Young, R.; Beckert, W. F. J. High Resol. Chrom. 1997, 20, 487.

7. Boyd-Boland, A. A.; Pawliszyn, J. B. J. Chrom. A. 1995, 704, 163.

8. Magdic, S.; Boyd-Boland, A. A.; Jinno, K.; Pawliszyn, J. B. J. Chrom. A. 1996, 736, 219.

9. Choudhury, T. K.; Gerhardt, K. O.; Mawhinney, T. P Environ. Sci. Technol. 1996, 30, 3259-3265.

10. Aguilar, C.; Penalver, S.; Pocurull, E.; Borrull, F.; Marcé, R. M. J. Chrom. A. 1998, 795, 105-115.

11. Eisert, R.; Levsen, K. J. Am. Soc. Mass Spectrom. 1995, 6, 1119.

12. Eisert, R.; Pawliszyn, J. J. Chrom. A. 1997, 776, 293.

13. Ferrari, R.; Nilsson, T.; Arena, R.; Arlati, P.; Bartolucci, G.; Basla, R.; Cioni, F.; Del Carlo, G.; Dellavedova, P.; Fattore, E.; Fungi, M.; Grote, C.; Guidotti, M.; Morgillo, S.; Müller, L.; Volante, M. J. Chrom. A. 1998, 795, 371. 